\title{
Assessment of the structural and functional impact of in-frame mutations of the $D M D$ gene, using the tools included in the eDystrophin online database
}

Aurélie Nicolas ${ }^{1,2,3}$, Céline Lucchetti-Miganeh ${ }^{1,3,4}$, Rabah Ben Yaou ${ }^{5,6}$, Jean-Claude Kaplan ${ }^{6,7,8}$, Jamel Chelly $y^{6,7,8}$, France Leturcq ${ }^{6,7,8}$, Frédérique Barloy-Hubler ${ }^{1,3,4,9}$ and Elisabeth Le Rumeur ${ }^{1,2,4,10^{*}}$

\begin{abstract}
Background: Dystrophin is a large essential protein of skeletal and heart muscle. It is a filamentous scaffolding protein with numerous binding domains. Mutations in the DMD gene, which encodes dystrophin, mostly result in the deletion of one or several exons and cause Duchenne (DMD) and Becker (BMD) muscular dystrophies. The most common DMD mutations are frameshift mutations resulting in an absence of dystrophin from tissues. In-frame DMD mutations are less frequent and result in a protein with partial wild-type dystrophin function. The aim of this study was to highlight structural and functional modifications of dystrophin caused by in-frame mutations.

Methods and results: We developed a dedicated database for dystrophin, the eDystrophin database. It contains 209 different non frame-shifting mutations found in 945 patients from a French cohort and previous studies. Bioinformatics tools provide models of the three-dimensional structure of the protein at deletion sites, making it possible to determine whether the mutated protein retains the typical filamentous structure of dystrophin. An analysis of the structure of mutated dystrophin molecules showed that hybrid repeats were reconstituted at the deletion site in some cases. These hybrid repeats harbored the typical triple coiled-coil structure of native repeats, which may be correlated with better function in muscle cells.

Conclusion: This new database focuses on the dystrophin protein and its modification due to in-frame deletions in BMD patients. The observation of hybrid repeat reconstitution in some cases provides insight into phenotypegenotype correlations in dystrophin diseases and possible strategies for gene therapy. The eDystrophin database is freely available: http://edystrophin.genouest.org/.
\end{abstract}

Keywords: Dystrophin, DMD gene mutations, Spectrin-like repeats, Duchenne muscular dystrophy, Becker muscular dystrophy, Phenotype-genotype correlation

\section{Background}

The Duchenne Muscular Dystrophy (DMD) gene, located on the short arm of the $\mathrm{X}$ chromosome (at $\mathrm{Xp21.2)}$, is the largest known gene in humans. It has an open reading frame of $\sim 11.055 \mathrm{~kb}$, containing 79 exons (Mendelian Inheritance in Man [MIM: 300377]) [1], and transcription from seven tissue-specific promoters leads

\footnotetext{
* Correspondence: elisabeth.lerumeur@univ-rennes1.fr

'Université de Rennes 1 Rennes France

2UMR CNRS 6026, Equipe RMN-ILP, Faculté de Médecine, CS 34317 Rennes Cedex 35043, France

Full list of author information is available at the end of the article
}

to the synthesis of 16 isoforms of the dystrophin protein. In humans, dystrophin diseases are caused by mutations in the $D M D$ gene and include the allelic phenotypes of Duchenne muscular dystrophy (DMD) [OMIM:310200], Becker muscular dystrophy (BMD) [OMIM:300376] and X-linked dilative cardiomyopathy (XLDCM) [OMIM:302045] [1-3].

Dystrophin is present at the internal face of the plasma membrane in many tissues, including skeletal, cardiac and smooth muscle, and in various central nervous system cells. Dystrophin is highly conserved in vertebrates, 
including mouse, chicken and dog, and in invertebrates, such as Drosophila [4], and Caenorhabditis elegans [5].

The full-length 3685-residue isoform of dystrophin, $\mathrm{dp} 427 \mathrm{~m}$, has a molecular weight of $427 \mathrm{kDa}$ and is expressed in skeletal and cardiac muscle, where it plays a key role during muscle contraction-relaxation cycles. Dystrophin has four main regions: (i) the N-terminal actin-binding domain (ABD) comprises the first 246 residues; (ii) the central rod domain spans residues 247 to 3045 (accounting for about $76 \%$ of the molecule $[6,7])$, is formed by 24 spectrin-like repeats and four hinges and binds to various partners (filamentous actin, membrane lipids and nitric oxide synthase); (iii) the cysteine-rich domain, from residues 3080 to 3360, binds to the intrinsic membrane protein $\beta$-dystroglycan and (iv) the carboxy-terminal domain, comprising the last 325 residues, binds to dystrobrevin and syntrophins (for reviews, see $[8,9])$. Dystrophin is associated with a large number of proteins, to which it either binds directly or with which it interacts indirectly through intracellular or extracellular proteins. The binding of dystrophin to $\beta$-dystroglycan brings it into contact with membrane and extracellular proteins to form the dystrophinglycoprotein complex (DGC) [10,11]. Dystrophin therefore forms a link between the extracellular matrix and cytoskeletal actin. The function of dystrophin is not completely understood, but its main role is to protect the sarcolemma from rupture during the stresses of muscle contraction [12,13].

Patients with muscular dystrophy have little or no dystrophin, and it has been suggested that this results in the disruption of muscle membranes, which alters calciumchannel activity, thereby strongly increasing intracellular calcium concentration. This ultimately leads to musclecell necrosis $[13,14]$, followed by regeneration. The continual cycles of regeneration and necrosis lead to the skeletal muscles being gradually replaced by adipose tissue and unable to sustain any mechanical activity.

The incidence of Duchenne muscular dystrophy (DMD) is about 1 in 3,500 male births. Affected patients have a massively reduced life expectancy and a poor functional prognosis. In most cases, DMD is due to frame-shift mutations in the $D M D$ gene, leading to a complete absence or low levels of dystrophin protein (no more than $3 \%$ normal levels). This accounts for the severity of the phenotype in all patients, although some variation of disease expression is observed between patients, in terms of motor, respiratory, cardiac and mental functions $[15,16]$. The expression of the various dystrophin isoforms may depend on the mutation site, potentially accounting, at least in part, for the correlation with the motor and mental status of patients [15]. Becker muscular dystrophy (BMD) is less frequent than DMD, and is usually milder, with slower disease progression. BMD is caused by in-frame deletions or duplications of one or several exons or by splice-site and missense mutations. These mutations lead to the production of various amounts of internally truncated, lengthened, or slightly modified dystrophin molecules. This results in a broad spectrum of clinical severity, ranging from a complete absence of symptoms, through mild disease, to severe clinical conditions similar to DMD [15-25]. According to the reading-frame rule, frame-shifting mutations lead to the severe DMD phenotype, whereas in-frame mutations lead to the less severe BMD phenotype [16,26]. However, there are exceptions to this rule, with certain in-frame mutations resulting in the severe DMD phenotype [27-31]. These mutations are frequently located at the 5 ' end of the gene encoding the $\mathrm{N}$-terminus of dystrophin including $\mathrm{ABD} 1$, or at the 3' end of the gene encoding the Cterminal domain, usually in the Cys-rich domain, thereby disrupting the DGC.

The structure and function of dystrophin are poorly resolved at the biological and physiological levels, and it is therefore difficult to establish a detailed phenotypegenotype correlation in BMD patients. Phenotypic differences between patients are thought to depend on the site of the deletion or duplication and the conservation of the reading frame, and such differences have recently been shown to be correlated with the residual amount of dystrophin [32]. Such knowledge is essential to anticipate the effects of current exon-skipping treatments on phenotype restoration in treated DMD patients [33-36].

Two databases of $D M D$ human mutations are already freely available online: the Leiden Muscular Dystrophy database $[37,38]$ and the UMD-DMD French database $[39,40]$. The Leiden Muscular Dystrophy database lists the $D M D$ mutations in patients reported in publications or submitted by contributors from around the world and includes some biochemical and phenotypic details. The UMD-DMD database provides molecular and clinical data for patients from France carrying a mutation of the $D M D$ gene. Both databases include in-frame and frameshifting mutations and focus on gene-level information. However, as dystrophin acts at the protein level, a more detailed and comprehensive characterization of the protein produced from genes with in-frame gene mutations is required. Such a characterization is particularly important for comparisons of the structural features and molecular interactions of the mutated protein with those of the wild-type protein. For example, the total absence of dystrophin, or its presence in very small amounts in DMD patients, leads to the breakdown of the DGC complex, a histological marker of the disease [41]. However, the site of the mutation determines whether these interactions are abolished in BMD patients, resulting in diverse phenotypes. For both basic research and clinical/ 
therapeutic purposes, it is therefore of interest to establish a correlation between the genotype and the molecular and structural consequences of in-frame mutations for the encoded protein.

To this end, we have developed a new database called eDystrophin, specifically dedicated to providing information about the in-frame mutations of the $D M D$ gene and their consequences for dystrophin molecules. The eDystrophin database includes both in-frame $D M D$ mutations identified at a routine diagnostic laboratory for these mutations in France and published mutations. In addition to the genetic and clinical details provided by the other two available databases, the eDystrophin database provides: (1) a synthetic view of the properties of mutated dystrophin, (2) a map of modifications to binding sites for interacting protein partners; for deletions involving the central rod domain, eDystrophin provides (3) a structural model of the mutation site and (4) a specific comment indicating whether a correct filamentous $3 \mathrm{D}$-structure is reconstituted around the mutation site. Finally, this new database focuses on the protein rather than the gene, providing a new vantage point regarding in-frame mutations of the $D M D$ gene, with the finding that the gene exons and protein domains are "in phase" for the specific central rod domain of dystrophin. This phasing controls the ability of the internally truncated dystrophin molecules to reconstitute a hybrid repeat unit able to fold into a triple coiled-coil, resembling the native repeats present in full-length dystrophin. This database is freely available from http://edystrophin.genouest.org/, and all the information provided can be downloaded.

\section{Methods}

eDystrophin is a relational database developed in MySQL 5.1.37 within the MAMP package [42]. The website was constructed with XHTML, PHP 5 and JavaScript. The database and the website are hosted by the BioGenouest platform [43] and run with the Apache web server, version 2.2.3. MyDomains [44] was used to represent the mutated proteins. The Jmol applet [45] is embedded for the visualization of three-dimensional structure-homology modeling.

\section{Database construction \\ Gene data}

The $D M D$ cDNA sequences for the seven known tissuespecific promoters and the positions of the 79 exons were obtained from GenBank (RefSeq in Table 1).

\section{Wild-type dystrophin data}

Sequence data for the 16 isoforms of wild-type dystrophin were downloaded from GenBank. Several of these isoforms are generated by alternative splicing in specific tissues (Table 1). The boundaries of the structural and functional domains were defined according to the findings of 19 published papers and three domainsearch tools (Additional file 1, Table S1). This resulted in the definition of 35 structural and 15 binding domains in the eDystrophin database (Figure 1A). All of the variants of each domain mentioned by the different authors are indexed in the database (See the "Knowledge" section), together with the original publication reference.

Two X-ray crystallographic structures of dystrophin domains have been reported: one for actin-binding domain 1 at the N-terminal end [PDB: 1DXX] [51] and the other for a WW domain and EF hand-region fragment complexed with a $\beta$-dystroglycan peptide [PDB: 1EG3] [52]. We recently used homology modeling to propose the three-dimensional structure models of the 24 central rod domain repeats [53]. The database gives models for isolated repeats (Figure 1B) and for tandem repeats (Figure $1 C$ ). Each repeat consists of three $\alpha$-helices: A, $B$, and $C$, and A, B', and C' for the following repeat. These two structures and all the structure models can be visualized and downloaded from the eDystrophin database (from the Explore database section).

\section{Data for mutated dystrophin}

Our principal goal was to provide information about the structure of the protein in cases of DMD in-frame mutation, as a valuable tool for exon skipping therapy. We collaborated with one of the two existing databases - the French UMD-DMD database [40] - resulting in the inclusion of all patients carrying in-frame mutations from the largest French cohort, for whom detailed genetic and molecular investigations had been carried out. Data from published studies reporting well characterized exon deletions/duplications were also included. The eDystrophin database compiles 209 different in-frame mutations from a total of 945 patients. One hundred of these mutations were described in previous studies, 67 were provided by the Laboratoire de Biochimie et Génétique Moléculaire (LBGM, Cochin Hospital, APHP, Paris) and 42 were present in both sources (Additional file 2, Table S2). The mutations are named according to Human Genome Variation Society nomenclature recommendations [54]. For each mutation, the cDNA sequence was predicted and is available from eDystrophin (See the "Explore database" section). As mRNA studies are rarely performed in cases of exon deletion/duplication, we did not consider mRNA levels in eDystrophin. For duplications, we cannot understand events at the protein level unless we know how the duplication is arranged at the gene level. We therefore assumed that repeats were in tandem and not in opposing directions, in which case a stop codon might occur, resulting in the absence of dystrophin and a DMD phenotype. The eDystrophin database also provides some general 
Table 1 DMD transcript variants and their tissue expression

\begin{tabular}{|c|c|c|c|c|c|}
\hline Promoters & Publication & Tissue specificity & Alternative splicing & mRNA RefSeq & Protein RefSeq \\
\hline $\mathrm{dp} 427 \mathrm{~m}$ & (Koenig et al., 1989)[16] & Skeletal muscle, heart muscle, glial cells & Not referenced & NM_004006.2 & NP_003997.1 \\
\hline dp427c & (Chelly et al., 1990)[46] & Brain, retina & Not referenced & NM_000109.3 & NP_000100.2 \\
\hline dp427p & (Chelly et al., 1990)[46] & Purkinje cells, muscle & Not referenced & NM_004009.3 & NP_004000.1 \\
\hline \multirow[t]{2}{*}{ dp260 } & (D'Souza et al., 1995)[47] & Retina & No but two alternative exon 1 & 1: NM_004011.3 & 1: NP_004002.2 \\
\hline & & & & 2: NM_004012.3 & 2: NP_004003.1 \\
\hline \multirow[t]{5}{*}{ dp140 } & (Lidov et al., 1995)[48] & Brain, kidney, retina & No splicing - > dp140 & NM_004013.2 & NP_004004.1 \\
\hline & & & Exons $71 \& 78$ - > dp140ab & NM_004022.2 & NP_004013.1 \\
\hline & & & Exon 78 - > dp140b & NM_004021.2 & NP_004012.1 \\
\hline & & & Exons 71 to $74 \& 78->$ dp $140 \mathrm{bc}$ & NM_004023.2 & NP_004014.1 \\
\hline & & & Exons 71 to $74->d p 140 c$ & NM_004020.3 & NP_004011.2 \\
\hline dp116 & (Byers et al., 1993)[49] & Schwann cells & Not referenced & NM_004014.2 & NP_004005.1 \\
\hline \multirow[t]{5}{*}{ dp71 } & (Hugnot et al., 1992)[50] & Everywhere except skeletal muscle & No splicing ->dp71 & NM_004015.2 & NP_004006.1 \\
\hline & & & Exons $71->$ dp71a & NM_004017.2 & NP_004008.1 \\
\hline & & & Exon $71 \& 78->d p 71 a b$ & NM_004018.2 & NP_004009.1 \\
\hline & & & Exon $78->d p 71 b$ & NM_004016.2 & NP_004007.1 \\
\hline & & & Stop at Exon $70->$ dp40 & NM_004019.2 & NP_004010.1 \\
\hline
\end{tabular}

clinical and protein information (see below) for each of the in-frame $D M D$ mutations. For each of the 209 protein sequences derived from these in-frame mutations, a map of the conserved and altered structural and binding domains of dystrophin was produced, including deletions of exons at the 3 ' end encoding actin-binding domain 1 (Figure 2A) and deletions of exons 13-44, 45-47 and 4548 (Figure 2B, C, D).

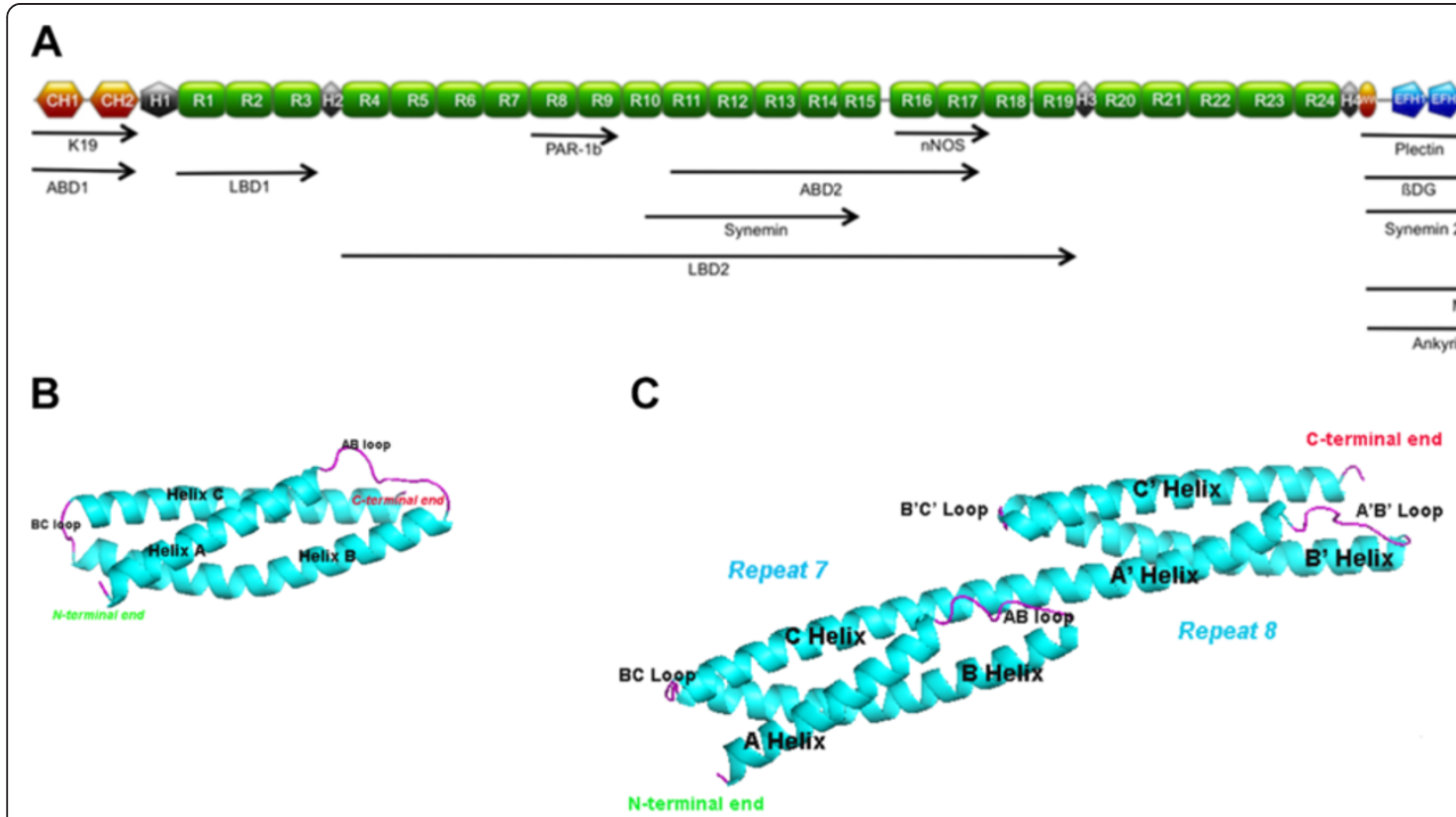

Figure 1 The dystrophin molecule and its partners. (A) Schematic representation of the molecule with the structural domains $\mathrm{CH} 1$ and $\mathrm{CH} 2$, constituting actin-binding domain 1, hinges 1 to 4 ( $\mathrm{H} 1$ to H4), spectrin-like repeats 1 to 24 (R1 to R24); the WW domain and EF hand-region constituting the Cys-rich domain; ZZ, the zinc finger domain; and the C-terminal domain (C term) and its partners. (B) Model of the threedimensional structure of repeat 7 folded into a triple coiled-coil, consisting of three helices, A, B, and C, joined by two loops, AB and BC. (C) Model of the three-dimensional structure of tandem repeats R7-8 of the rod domain. Each repeat is composed of three alpha helices folded into a triple coiled-coil: R7 (helices $A, B$, and $C$, joined by loops $A B$ and $B C$ ) and $R 8$ (helices $A^{\prime}, B^{\prime}$ and helix $C^{\prime}$, joined by loops $A^{\prime} B^{\prime}$ and $B^{\prime} C^{\prime}$ ). $A$ long common helical linker is formed between the two repeats by $R 7$ helix $C$ and $R 8$ helix $A^{\prime}$. 


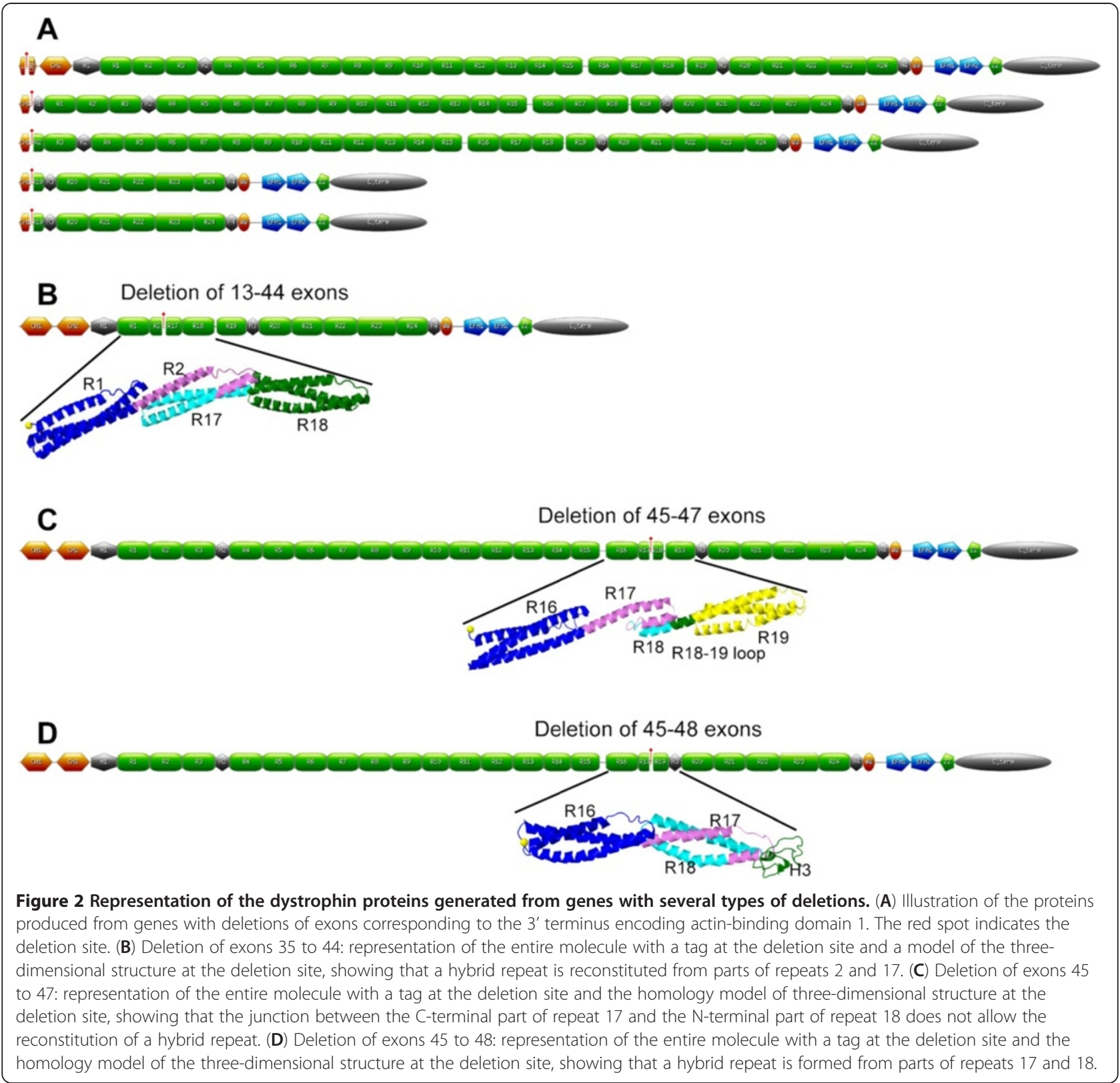

For each deletion of exons encoding part of the central rod domain (exons 10-61), homology modeling was used to determine the structure of the protein at the junctions on either side of the deletion. Homology modeling was performed on the automated server, I-TASSER $[55,56]$, as in our previous study on native repeats [53]. I-TASSER combines various techniques, including threading, $a b$ initio modeling and structure-refinement approaches, for the prediction of protein structures. For each submitted sequence, one to five models are produced based on homology to the spectrin repeats, the crystallographic structures of which have been resolved. Briefly, the C-score in I-TASSER estimates the quality of the predicted model, based on the significance of the threading alignments and the convergence of the simulations. $\mathrm{C}$-score values typically lie in the range of -5 to 2 , with higher scores indicative of a better model. Only the model with the best $\mathrm{C}$-score is retained in the eDystrophin database. Furthermore, three-dimensional structure models of isolated hinges were submitted to I-TASSER and were incorporated into models as necessary. These new structures, made of separated blocks, were minimized twice, in water and $50 \mathrm{mM} \mathrm{NaCl}$. The models were further analyzed by graphical display with PyMOL [57] and evaluated with PROCHECK (to check the stereochemistry information supplied by ProSA-web 
[58,59]) and Verify3D [60,61] (for structure validation). Ramachandran plots showing the amino-acid distribution are provided by eDystrophin, indicating the energetically favorable regions for peptide bond torsion angles for each amino-acid of the protein. The structural model is considered of higher quality if the distribution of amino-acid torsions is restricted to the regions allowed in the plot.

The models can be visualized online with Jmol [45], using a color code for each region of the protein. Comparison of the structure of the mutated protein with native repeat folding is provided by eDystrophin, through a static view of a native three-repeat fragment of dystrophin in a parallel box. Static images and PDB files for the wild-type and mutated models can be downloaded.

\section{Clinical data}

In total, 945 clinical records (531 provided by the LBGM and 414 from published studies) were included in eDystrophin. The database provides a brief description of the disease phenotype corresponding to the most commonly used clinical classification. The DMD and BMD phenotypes are attributed to cases in which the patient loses the ability to walk before the age of 13 years and after the age of 16 years, respectively. The intermediate muscular dystrophy (IMD) phenotype is used to describe patients who stopped walking between the ages of 13 and 16 years. The DCM phenotype is attributed to the subgroup of patients with isolated cardiomyopathy without skeletal muscle involvement, whereas the "pending" subgroup corresponds to patients with insufficient clinical data for correct classification of their phenotype. Finally, the "asymptomatic" phenotype is assigned to patients with no myopathic or cardiac symptoms at their most recent check-up.

The results of dystrophin immunostaining and/or western blot studies with three specific antibodies against different domains of dystrophin were available for 360 patients. The Dys-1 antibody is specific to repeats 8-9 in the central rod region; the Dys- 2 antibody is specific to the C-terminus (residues 3669-3685); and the Dys-3 antibody is specific to the $\mathrm{N}$-terminus (residues 321-494). For the LBGM patients, data from immunostaining studies are presented according to staining regularity (normal, regular, irregular, mosaic, no signal with revertant fibers, and no signal) and intensity (high, medium, and low). Western blots with the same three antibodies were used to assess the quantity (high, medium or low) and size (increased, normal, reduced or undetected) of the three major regions of the mutated protein. Thus, for each of the recorded in-frame mutations, the eDystrophin database displays the percentage of patients carrying the mutation with resulting in the production of low, normal or high levels of dystrophin proteins of small, normal or large size. In addition, for cases in which clinical data are available, the presence of cardiomyopathy or mental retardation at the last clinical examination is also displayed. The aim of eDystrophin was not to provide detailed descriptions of clinical symptoms, dystrophin immunofluorescence and western blot status for each patient, but a global view for each subgroup of patients carrying the same in-frame $D M D$ mutation.

\section{Results}

\section{Website organization}

The eDystrophin website contains four distinct sections: "Knowledge", "Explore database", "Statistics" and "Links". The "Knowledge" pages provide background information about the dystrophin gene and protein, the diseases associated with mutations of the gene and current celland gene-therapy strategies. The "Explore database" pages contain data that can be downloaded, and this section is divided into two parts: 'Wild-type dystrophin', and 'Mutated dystrophin'. The "Statistics" section provides a brief summary of statistics for eDystrophin content. Finally, the "Links" section provides some useful links and a list of previous publications reporting well characterized exon deletions/duplications implemented in eDystrophin.

The 'Wild-type dystrophin' pages provide all of the wild-type sequences and the corresponding threedimensional structures of the domains. The cDNA and protein sequences of the 16 isoforms can be obtained by clicking on the "Isoform full-length sequences" tab. A diagram of the organization of the cDNA can be obtained by clicking on the "Exon sequences" tab, and the sequences of the 79 exons can be obtained by clicking on the chosen exon. The sequences of the various domains, with all of the versions reported in published studies, can be obtained by clicking on the "Structural domain sequences" tab, and a diagram of dystrophin with the functional domains reported in published studies can be obtained by clicking on the "Binding domain sequences" tab. By clicking on the domain, the user can download the sequence. Similarly, the three-dimensional structures found in $\mathrm{PDB}$ are available via the " $3 \mathrm{D}$ structure models" tab, as are the homology-based models of all single and tandem repeats, which can be visualized with the Jmol vizualization tool [45].

The "Mutated dystrophin" pages are dedicated to the 209 in-frame mutations of the human DMD gene included in eDystrophin. It is possible to search for mutations according to mutation type, phenotype or the domain involved.

The "Search by mutation type" tool allows the user to search for deletions, duplications or substitutions. If "Deletions" or "Duplications" are selected, a diagram of the exons of the $D M D$ gene is displayed (as in Figure 3). This allows the user to select an exon, for which a list of all deletions or 


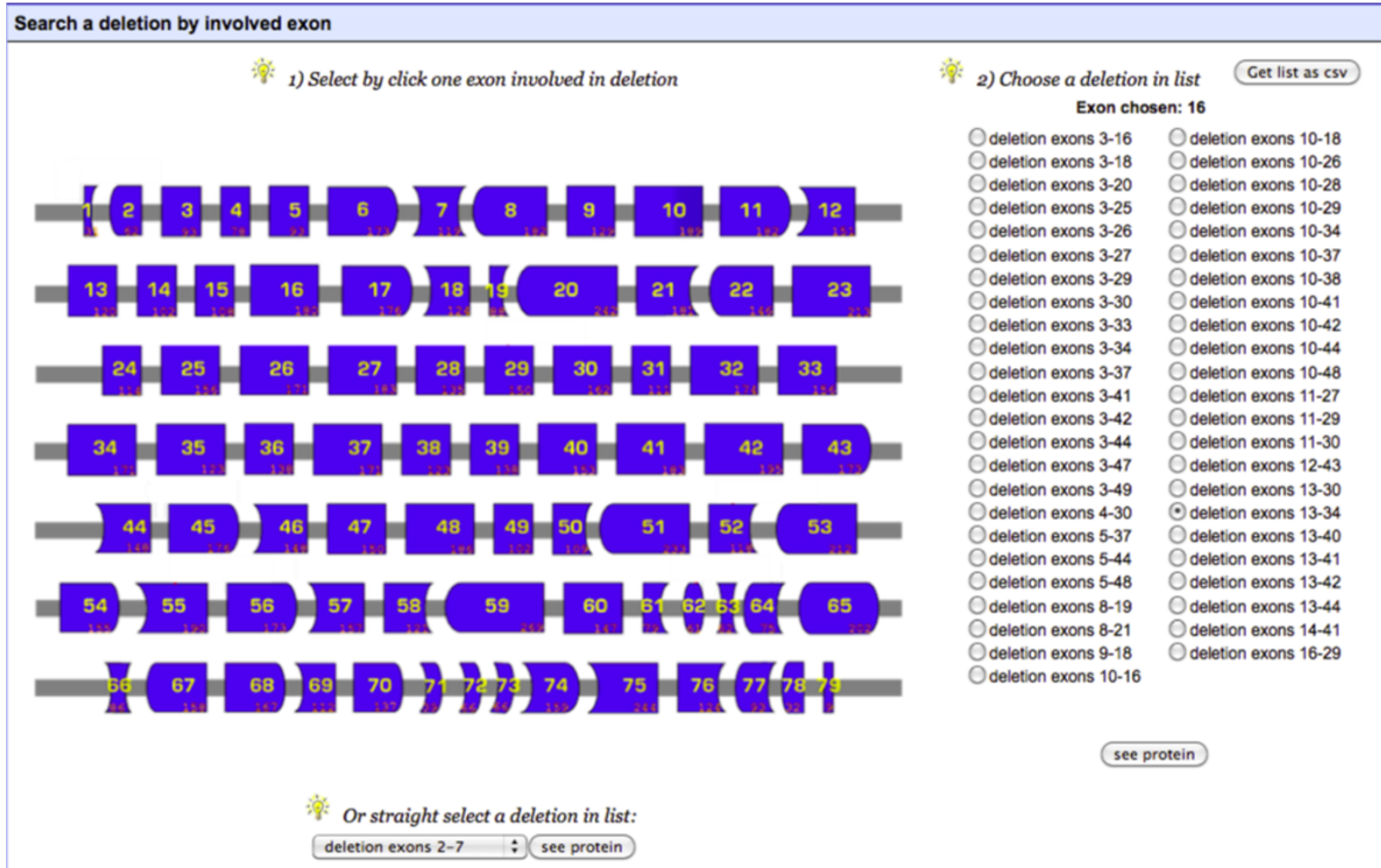

Figure 3 Screenshot of "Search by mutation type/Deletions" tool. The user can select an exon and then a deletion involving this exon. On the right side of the page, the user can select a mutation of interest from a list, to obtain data about this mutation. The user can also save this list as a csv-format file.

duplications affecting this exon can then be obtained, or to select a mutation of interest from the list at the bottom of the page. If "Substitutions" is selected, a list of mutations is provided. The "Search by phenotype" tool provides a list of mutations "affecting at least one patient" or "affecting no patient" with a specific phenotype. These phenotypes include pending or asymptomatic, BMD, IMD, DMD or DCM. The "Search by involved domain" tool provides a representation of the dystrophin protein, together with its known partners. The names of the structural domains and partners of dystrophin are active buttons. Clicking on these buttons brings up a list of mutations affecting the chosen domain or partner. All of these mutation lists are easy to save down as a csv-formatted data file.

Regardless of the way in which the list of mutations was obtained, clicking on the "see protein" button opens a new page showing a summary table with a global view of the effects of the mutations and four horizontal tabs displaying details (Figure 4A). By clicking on the "Clinical data' tab, the user can obtain the number of patients listed in the database carrying a given mutation, and information about the overall distribution of phenotypes, the severity of the disease in BMD patients, the presence or absence of cardiomyopathy and mental retardation and the size and amount of dystrophin (when such data are available) (Figure 4B).

Clicking on the "Protein structural domains" tab provides a map of the protein domains modified by the mutation and a table summarizing the consequences of the deletion for the four shorter dystrophin isoforms (Figure 4C). Similarly, clicking on the "Protein binding domains" tab brings up a map of modifications to the binding domains of the mutated protein (Figure 4D). Finally, clicking on the "3Dstructure model of the mutation site" tab provides the user with a model of the three-dimensional structure of the regions on either side of the mutation in cases in which exons encoding part of the central rod domain are deleted (Figure 4E). The user can freely download a PDF summary file including the clinical data described above, information about structural and binding domains and the threedimensional structure model. A final comment about the impact of the mutation on the filamentous structure of the protein is also provided.

\section{Overview of the content of the database Statistics}

The 209 mutations recorded in the eDystrophin database include 128 large deletions of one or several exons 


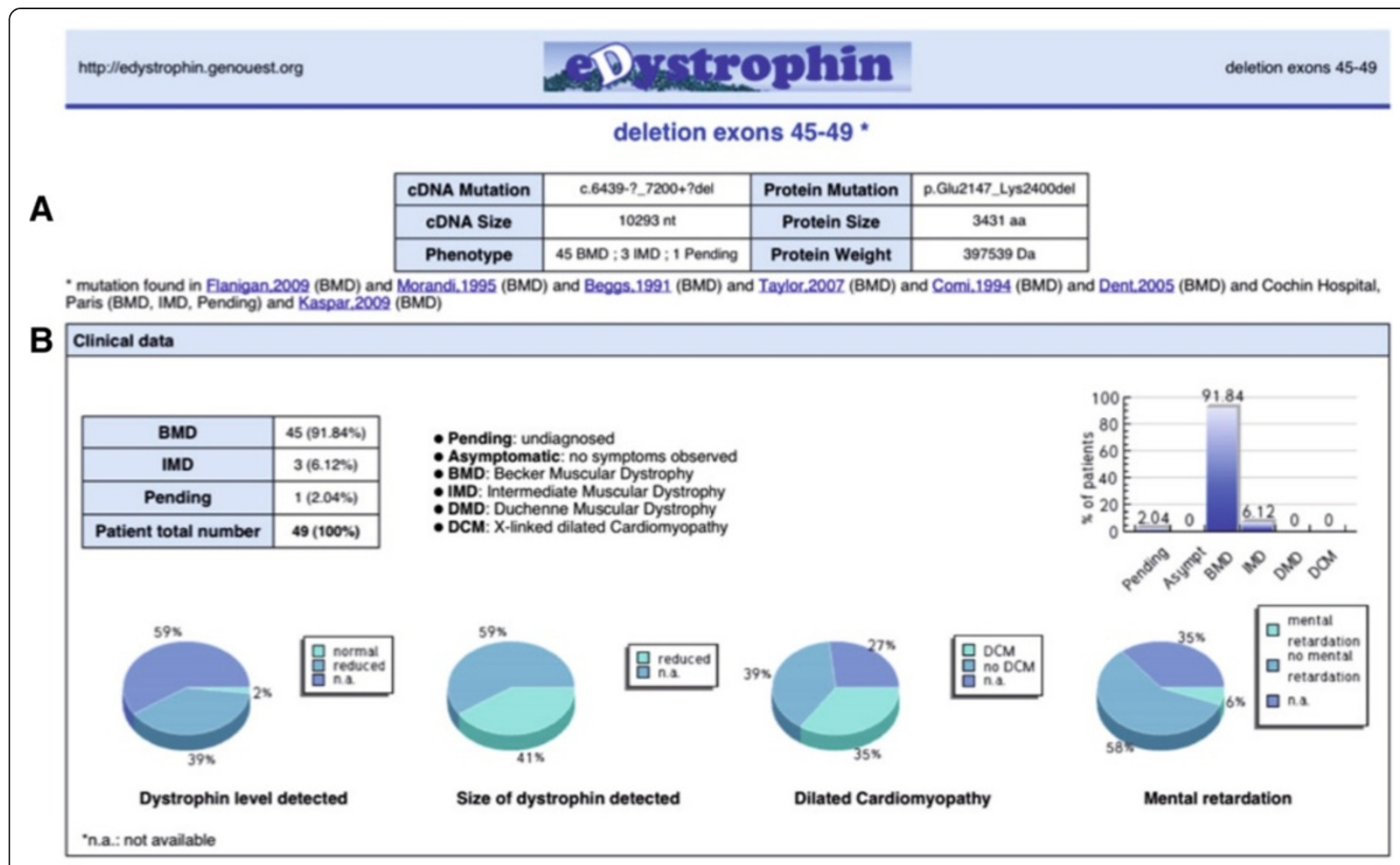

http:/ledystrophin.genouest.org

C

Protein Structural Domains

00

\section{\begin{tabular}{ll} 
Dystrophin isoforms \\
\hline
\end{tabular}}

\begin{tabular}{|c|c|c|c|}
\hline Dp260-1 & Dp140 & Dp116 & Dp71 \\
\hline Same mutation as dp427m above & $\begin{array}{c}\text { Mutation in promoter: } \\
\text { unknown consequences at protein level }\end{array}$ & isoform not affected by the mutation & Isoform not affected by the mutation \\
\hline
\end{tabular}

D Protein Binding Domains

\begin{tabular}{|c|c|c|c|c|c|c|c|c|c|}
\hline K19 & present & ABD1 & present & LBD1 & present & LBD2 & partial, center & PAR-1b & present \\
\hline ABD2 & partial, N-term & Synemin & present & $\mathrm{nNOS}$ & partial, N-term & Plectin & present & BDG & present \\
\hline Syntrophin & present & Dystrobrevin & present & Synemin2 & present & Myospryn & present & Ankyrin & present \\
\hline
\end{tabular}

E 3D-structure model of the mutation site

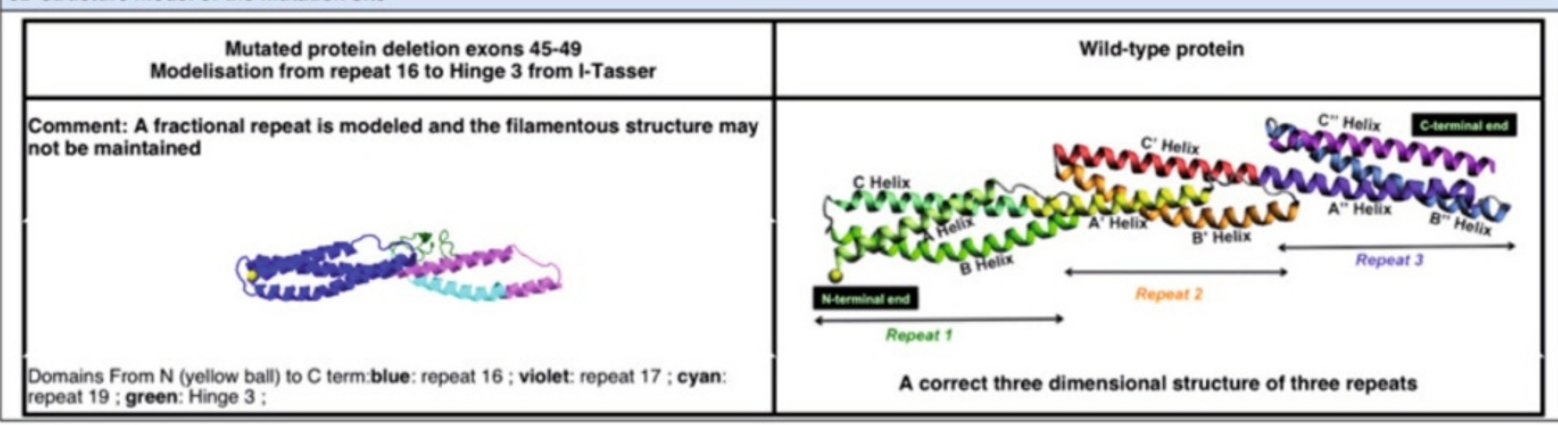

Figure 4 (See legend on next page.) 


\section{(See figure on previous page.)}

Figure 4 Screenshot of data available for the deletion of exons $\mathbf{4 5}$ to $\mathbf{4 9}$. (A) A general view of the webpage after loading. Description of the mutation at the nucleotide and protein levels, CDNA and protein size, the molecular weight of the mutated protein, a link to CDNA and protein sequences and a list of references reporting patients carrying the mutation are available in table form. Detailed information about clinical data, structural and binding domains and models of three-dimensional structure can be obtained by clicking on the boxes below. (B) The "Clinical data" tab on the first line provides access to a table showing the distribution of phenotypes. In the second line, pie-charts showing the amount and size of dystrophin, as determined by western blotting, the presence of cardiomyopathy and mental retardation are given. (C) The "Structural domains" tab provides a schematic representation of the mutated dystrophin. The sequences of each protein domain are available. (D) The "Binding domains" tab indicates, in red, the changes to the binding domains caused by the mutations listed in the table. (E) The "3D-structure model of the mutation site" tab shows the model of the three-dimensional structure of the domains around the mutation junctions (here R16, R17, R19 and H3). The secondary structure predicted by I-TASSER is displayed above the model. The PDB file and the Ramachandran plot are also available. The modeling tab is available only for the deletion of exons encoding part of the central rod domain. All information can be saved down in the form of PDF files.

(61\% of the mutations listed) and 50 large duplications of one or several exons (24\% of the mutations). There are also 23 missense mutations (11\%), and 8 small inframe deletions $(4 \%)$ (Figure 5A).

Figure 5B shows the phenotype distribution for all the patients. Of the 945 patients, 733 (78\%) had the BMD phenotype, 131 (14\%) had the DMD phenotype (most of these patients had mutations towards the 3 ' end of the $D M D$ gene), and 20 patients (2\%) had the IMD phenotype. Thus, $16 \%$ of the patients registered in the eDystrophin database are exceptions to the Monaco rule [26], as they carry in-frame mutations associated with the severe DMD/IMD phenotypes. Deletions of exons 60 to 79 are generally observed only in DMD patients, but deletions of exons 45-79 and of exon 60 have been reported in at least one BMD patient (Additional file 3 Figure S1A, B). This is consistent with previous reports showing that deletions involving the Cys-rich domain are more deleterious than mutations involving the central rod domain. Similarly, 18

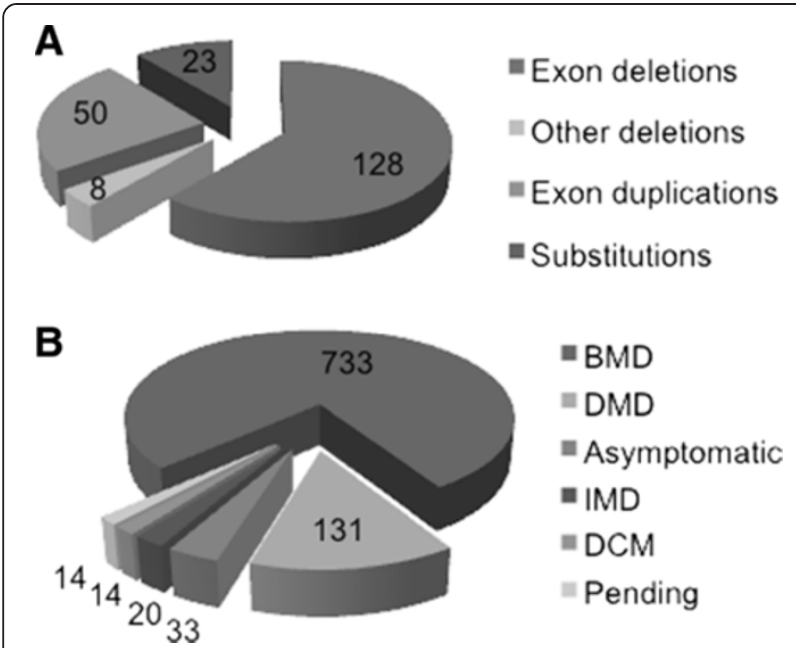

Figure 5 Statistics for mutations recorded in the eDystrophin database. (A) Mutation types: the number of cases is shown for each of 209 different mutations. (B) Phenotype distribution: for each phenotype, the number of patients concerned, from a total of 945 patients, is shown. mutations starting at exon 3 have been found in at least one DMD patient, whereas only nine such mutations have been found in at least one BMD patient. As previously reported, deletions affecting ABD1 were generally found to be more deleterious than those affecting the central domain $[23,40]$. Twenty-nine of the deletions involving the central domain were found in at least one DMD patient, whereas 60 were found in at least one BMD patient. Thirty-one of the duplication mutations were observed in at least one DMD patient (Additional file 3, Figure S1C,D), and 24 were observed in at least one BMD patient. These findings indicate that duplications are generally more deleterious than deletions.

\section{Case studies}

We illustrate the use of the eDystrophin database for analysis of the consequences of a specific in-frame $D M D$ mutation, by studying two exon deletions: deletion of exons 13-44 (c.1483-? 6438 + ?del; p.Val495_Lys2146del) which is a proximal large deletion with a low frequency, and deletion of exons 45-47 (c.6439-?_6912 + ?del; p.Glu2147_Lys2304del), a very frequent, distal, relatively short deletion. The easiest way to proceed is to select one of the mutated exons from the "Mutated dystrophin" page and then to click on the "Search by mutation type"/"deletions" tabs. The desired mutation is chosen and the "see protein" tab is clicked to view the results page.

As shown in the summary at the top of the new page, the deletion of exons 13-44 has been observed in only one BMD patient ("Clinical data" tab). This deletion leads to the production of a 2033-residue dystrophin protein with a molecular weight of $234 \mathrm{kDa}$, which is smaller than its wild-type counterpart (3685 residues and a molecular weight of $427 \mathrm{kDa}$ ) and was originally reported in [22]. All the data on the page can be downloaded as a pdf file, by clicking on "Get pdf file". The "Protein structural domains" tab shows that the region from the $\mathrm{C}$-terminal part of repeat 2 to the $\mathrm{N}$-terminal part of repeat 17 (including hinge 2), is missing from the mutated protein (Figure 2B). Furthermore, this deletion 
affects the promoter of the Dp260 and Dp140 isoforms but has no effect on Dp116 and Dp71. The "Protein binding domains" tab shows that the deletion encompasses the entire PAR-1b and synemin-binding domains and partly modifies the LBD1, LBD2, ABD2, and nNOS binding domains. Clicking on the "3D-structure model of the mutation site" tab brings up the I-TASSER-built three-dimension structural model, showing that a long helix is reconstituted at the mutation site junction between the $\mathrm{N}$-terminal part of repeat 2 and the $\mathrm{C}$-terminal part of repeat 17 (Figure 2B). Thus, the reconstitution of a triple coiled-coil, as in the wild-type three-repeat model, may occur. This I-TASSER model has a C-score of 0.66, indicating a correct fold, as confirmed by Verify3D, ProSA-web and Procheck, all of which indicated a high overall quality for the model. The Ramachandran plot showed that $91.7 \%$ of the residues were in the most favored regions, with $1.7 \%$ of residues in disallowed regions. These disallowed residues are located in loops, which are often poorly defined. These values are compatible with a crystal structure. As shown in the box, we can therefore conclude that a correct filamentous three-dimensional structure, in the form of a hybrid repeat generated by the concatenation of two truncated repeats, is reconstituted at the new junction. Such a hybrid repeat was hypothesized for the deletion of exon 41-42 in an in vitro experiment. The author of the study concerned concluded that this hybrid repeat is viable and has some of the properties of the native repeat [62].

The second case study is that of the deletion of exons 45-47. Unlike the first example, this deletion is very frequent, having been observed in 223 patients (23.6\% of the eDystrophin cohort). The resulting protein is 3527 residues long, with a calculated molecular weight of $409 \mathrm{kDa}$. The "Clinical data" tab shows that the observed phenotypes correspond to BMD in $96 \%$ of patients, associated cardiomyopathy in $19 \%$ of patients, and features suggesting mental retardation in $2 \%$ of patients. Dystrophin protein levels were reported to be lower than normal in $30 \%$ of the patients and normal or high in $1 \%$ of patients, with no data available for the remaining patients. The protein was small in $30 \%$ of patients and of normal size in $3 \%$ of patients, with no data available for the remaining patients. Thus, data concerning the amount and size of the dystrophin protein are missing for $67 \%$ of the patients. The "Protein structural domains" tab shows that the deletion eliminates the C-terminal end of repeat 17 and the $\mathrm{N}$-terminal end of repeat 18 (Figure 2C). Dp260 is deleted, along with Dp427m and the Dp140 promoter is affected by the deletion, but the wild-type Dp116 and Dp71 isoforms are unaffected. The "Protein binding domains" tab shows that the ABD2, LBD2, and nNOS binding domains are partially modified by this deletion. As can be seen by clicking on the "3Dstructure model of the mutation site" tab, the junction region on either side of the mutation is correctly folded, consistent with the findings of Verify 3D and ProSAweb analysis. The Ramachandran plot shows that $90.2 \%$ of the residues are in the most favored regions, and 1.6\% residues are in disallowed regions, specifically in loops between helices. However, the model also includes small helices that do not reconstitute a triple coiled-coil (Figure 2C). This implies that no hybrid repeat reconstitution occurs at the junction, with a fractional repeat formed instead and resulting in an incorrect filamentous $3 \mathrm{D}$ structure. The term "fractional repeat" has previously been used to describe the joining of two truncated repeats without the reconstitution of a triple coiled-coil similar to that observed in native repeats $[62,63]$. This conclusion is again displayed in the box.

\section{Exon phasing versus repeat phasing}

The triple coiled-coil structure of the wild-type dystrophin repeats requires the amino-acid sequences to have a seven-residue pattern (the heptad), with apolar residues located alternately three and four residues apart. The $\alpha$-helices assemble such that they are tilted and coiled around one another, each in an opposite direction to the other helices. This generates the multistranded structure of the coiled-coil $[64,65]$. Such structures may be formed from two or three helices. Like all spectrin-like repeats, dystrophin repeats consist of three helices. As shown above, exon deletions may or may not allow the reconstitution of a triple coiled-coil at the junction between the sequences on either side of the deletion.

Comparison of the heptad pattern of the repeat alignment obtained by Winder [7] with the exon boundaries showed that all the B helices were encoded by two successive in-frame coding exons (Additional file 3, Figure S1). A simplified diagram of this global organization of exons and repeats in the central rod domain of dystrophin is shown in Figure 6A. Each line represents a repeat or a hinge. The exons encoding the repeats are represented by rectangles, with alternating colors for clarity: even-numbered exons are shown in orange and odd-numbered exons are shown in light yellow. In all the repeats other than repeat 14, the $B$ helices appear to be encoded by two successive in-frame exons with the boundaries precisely aligned with the third heptad of the B helices (Additional file 4, Figure S2).

Thus, an in-frame deletion of two successive exons, the first of which encodes the C-terminal part of a B helix, would be expected to result in deletion of the end of this $B$ helix and of the $C$ helix of the first repeat, together with the beginning of the $\mathrm{B}$ helix of the following repeat. This deletion results in a concatenation of the first part of the $B$ helix of the first repeat with the second part of the $B$ helix of the second repeat. Consequently, the heptad pattern remains similar to that in wild-type dystrophin, and 


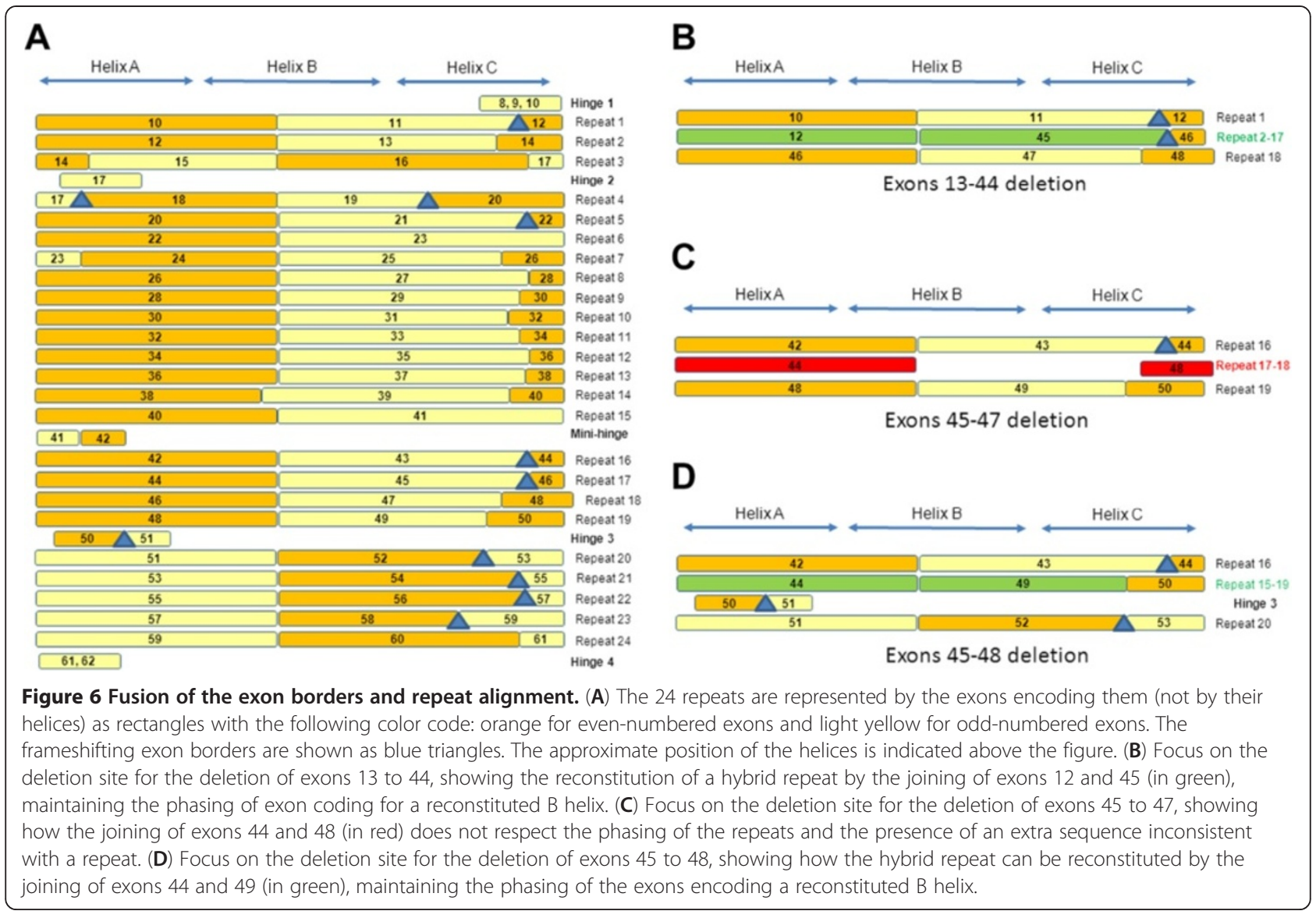

the domain can fold like a native repeat, thereby constituting a hybrid repeat. This observation confirms the previous report of an observation of a hybrid repeat [62]. A similar phenomenon may occur for many deletions involving two such exons or multiples of two exons. In situations in which the formation of a hybrid repeat is not possible, fractional repeats, in which the heptad pattern of alignment is not respected at the new junction between the sequences on either side of the deletion, may form, as previously suggested [63].

\section{Discussion}

The eDystrophin database is a new biomedical resource for clinicians and researchers working on human dystrophin diseases. This dedicated database for the dystrophin protein specifically aims to provide information about in-frame $D M D$ mutations and their consequences for the dystrophin protein. It provides a framework for the analysis of such mutations, by presenting a large body of information for both wild-type and mutated dystrophin proteins, including findings relating to the structure of these proteins and their interactions with known partners. Although eDystrophin is a locus-specific database, it was not constructed with an existing database system, such as LOVD [66,67] or UMD [68,69]. Indeed, such systems are more useful for DNA variant databases and are not suitable for the construction of a proteinbased database like eDystrophin.

In human dystrophin diseases, the ratio of the frequency of $\mathrm{DMD}$ to that of $\mathrm{BMD}$ is approximately $2 / 3-1 / 3[40,70]$. Most cases of DMD are caused by frame-shift mutations, whereas BMD is generally caused by in-frame mutations, although exceptions have been reported [26]. Documented cases of in-frame mutations are largely underrepresented in existing databases, and the primary aim of the eDystrophin database project was to redress the balance, by developing a dedicated information source for in-frame mutations. Unlike frame-shift mutations, in-frame mutations lead to the production of proteins with various degrees of functionality. The secondary goal of eDystrophin was therefore to determine and show the predicted consequences of these mutations for the composition and structure of the encoded proteins and their clinical consequences. In this first version of eDystrophin, patients and in-frame mutations were obtained from one of the major French contributors to the UMDDMD database and from published studies. Evidently, the database could be expanded in the near future by 
including mutations and patients from around the world, which would probably yield more accurate phenotypegenotype correlations.

However, dystrophin is a large protein, and it is a challenge to investigate the consequences of mutations of its gene. The dystrophin protein has two principal roles: as a scaffolding protein for several interacting partners and as a filamentous protein with a mechanical and structural function, providing resistance to the stress of muscle contraction $[8,13]$. Any mutation altering the structure of dystrophin may therefore affect both these functions (and potentially other minor functions of the protein as well) simultaneously. Our database provides an overview of the effects of mutations on protein function. In particular, it provides the user with information about changes to interactions and about the maintenance or disruption of the filamentous structure of the mutated dystrophin protein.

Several binding partners of dystrophin have been identified, and the eDystrophin database infers changes to their binding to a mutated dystrophin variant by considering whether the interacting domains remain intact and unmodified. Based on these inferences and previous observations, deletions affecting the Cys-rich or ABD1 domains appear to be much more deleterious than those affecting the central domain [23,40]. However, we detected several mutations affecting the central rod domain and causing a DMD phenotype in a substantial number of patients. In these patients, mRNA levels may have been low and/or unstable, accounting for the presence of little or no protein. Careful re-examination of the boundaries of the mutation is also necessary for these patients. Indeed, Taylor et al. (2007, PhD thesis) re-examined a large cohort of DMD patients with inframe deletions affecting the central rod domain and found that most were frame-shift mutations, consistent with the Monaco reading frame rule. Furthermore, we cannot entirely exclude the possibility of two mutations occurring in the same gene. For the other DMD patients carrying in-frame mutations, uncertainties remain concerning the levels or stability of the corresponding mRNA.

We obtained models of the three-dimensional structure of the new junctions created between the sequences on either side of the deletions in the central rod domain, as previously described [53]. The database provides a computational model for each in-frame deletion collected. An analysis of the structural features of these new junctions showed that two outcomes were possible: the reconstitution of a hybrid repeat and the formation of a fractional repeat in situations in which it was not possible to form a hybrid repeat. The likelihood of hybrid repeat formation depends on the phasing of the exon boundaries with the center of the B helix of the repeats. The reconstitution of a hybrid repeat can be assumed to occur because the major factor controlling this folding pattern is the presence of a heptad pattern. As this pattern is respected in cases in which the deletion creates a new junction between the first half of one $B$ helix and the second half of the next, from two truncated repeats, coiled-coil folding similar to that in native repeats would be expected $[64,65]$. By contrast, in fractional repeats, the $\alpha$-helices can fold correctly, but the heptad pattern is not respected and a three-dimensional coiled-coil structure therefore cannot be obtained. This may result in a less stable deletion site than for native and hybrid repeats. The hypothesis that repeats phasing in truncated dystrophins is essential to ensure a high level of protein function has already been tested. Transgenic $m d x$ mice were produced with several types of truncated dystrophin, some with correct and others with incorrect phasing of the repeats. However, in this previous study, native repeats were either entirely conserved or entirely lost [71]. These findings led to the "minidystrophin" concept for DeltaH2-R19, in which the rod domain was decreased in size by a deletion encompassing the amino acids from hinge 2 to repeat 19. By contrast the "micro-dystrophin" DeltaR4-R23 had a deletion extending from repeat 4 to repeat 23 . Constructs encoding these proteins proved to be among the best therapeutic constructs for $m d x$ mouse rescue. In BMD patients, phasing is not as described in these previous experiments and only hybrid repeats may be reconstituted. However, the demonstration of beneficial effects of phasing in the $m d x$ mouse suggests that the presence of hybrid repeats may be associated with a milder phenotype than the presence of fractional repeats $[62,63]$. Such a correlation between the structural features of mutated dystrophin and clinical severity in a cohort of BMD patients has been reported for cardiomyopathy [24]. The authors constructed models of the mutated dystrophin for deletions involving exons 45 to 49 and investigated the phasing of spectrin repeats. They concluded that the absence of hinge 3 delayed the onset of dilated cardiomyopathy.

However, it should be stressed that the presence of a hybrid repeat does not itself imply a better conservation of dystrophin function than the presence of a fractional repeat. Indeed, mRNA instability or changes to protein-protein interactions may also affect the function of the mutated dystrophin, and it is not currently possible to predict these effects. Investigations of the correlation between the presence of a hybrid repeat and the severity of clinical symptoms are now required. However, the eDystrophin database can be used as a predictive tool for exon skipping-based therapy. The choice of the exon to be deleted to restore the reading frame could be based on careful consideration of the likelihood of reconstituting a hybrid repeat. 


\section{Conclusions}

The eDystrophin database is a new tool providing an overview of the proteins generated by $D M D$ genes carrying in-frame mutations. It provides information about the consequences of these mutations for protein production and folding and for phenotype-genotype correlations. This database, through these features, is thus a valuable tool for predicting the efficacy of exon-skipping therapy for DMD patients.

\section{Supporting data}

The supporting datasets are provided within the article and the additional files.

\section{Additional files}

Additional file 1: Table S1. provides the references from which information about the structural and binding domains of dystrophin described in eDystrophin was obtained [7,51,52,72-90].

Additional file 2: Table S2. provides the origin of the mutations described in the eDystrophin database [18,20,22,24,91-102].

Additional file 3: Figure S1. Statistics for mutations included in eDystrophin. Exon deletions (A, B) and duplications (C, D) associated with at least one $\mathrm{DMD}(\mathrm{A}, \mathrm{C})$ or one $\mathrm{BMD}(\mathrm{B}, \mathrm{D})$ patient. Each line represents a type of exon deletion ( $A$ and $B$ ) or duplication ( $C$ and $D)$.

Additional file 4: Figure S2. Sequence alignment of the 24 spectrin-like repeats of dystrophin. Repeats were aligned by ClustalW, using default parameters, as described by Winder et al. [7]. The alignment was visualized in Jalview. In the first line, heptad motifs are indicated, showing the hydrophobic residues in the (a) and (d) positions. The repeat numbers and the number of residues per repeat are indicated at the start of the repeat sequence. The presence of absence of hinges 2 and 3 is indicated in separate lines. There are two extra sequences at the ends of repeats 15 and 18 not aligned with the heptad pattern. The presence of these sequences is indicated at the end of the corresponding lines. At the end of each line, the numbers of the exons encoding the repeat are indicated in parentheses. The repeat sequence are highlighted alternately in orange (even-numbered exons) and light yellow (odd-numbered exons). The rectangle indicates the middle of the $B$ helices of the repeats. If the successive exons are not in frame, the residues are shown in red. The alignment reported by Koenig et al. [76] is also mentioned: the residues at the start of the repeats are underlined when they differ from Winder's alignment.

\section{Competing interests}

The authors declare that they have no competing interests.

\section{Authors' contributions}

ELR, FBH, RBY and JC initiated and supervised the project. AN, CLM and FBH created the database. AN, RBY, FL and ELR monitored data collection. AN and ELR created and analyzed the structural models. ALL authors participated in the writing of the manuscript and approved its submission.

\section{Author's information}

Frédérique Barloy-Hubler: IFR GFAS - http://ifr140.univ-rennes1.fr/platesformes/Amadeus/.

\section{Acknowledgments}

We thank the "Association Française contre les Myopathies" and "IFR 140" for providing funding for this work. We also thank the referring physicians both within and outside the French CORNEMUS network (Coordination des centres de Référence Neuromusculaires), for their valuable collaboration and for providing the clinical information used. We thank Michael Buckley for interesting discussions and for providing us Peter Taylor's thesis. We also thank the Prosite team for modifying the MyDomains tool for use in our database, and Biogenouest, which hosts the database. AN was supported by the CNRS

\section{Author details}

'Université de Rennes 1 Rennes France. ${ }^{2}$ UMR CNRS 6026, Equipe RMN-ILP Faculté de Médecine, CS 34317 Rennes Cedex 35043, France. Université Européenne de Bretagn 5, Boulevard Laënnec, Rennes 35000, France. ${ }^{4}$ UMR CNRS 6026, Equipe SP@RTE Campus Beaulieu, Rennes cedex 35042, France. ${ }^{5}$ Département de recherche clinique, Institut de Myologie, GH PitiéSalpétrière Paris, France. ${ }^{6}$ Laboratoire de Biochimie et Génétique Moléculaire-Hôpital Cochin, Paris France. ${ }^{7}$ Institut Cochin, CNRS UMR 8104, Inserm U 1016, Université Paris Descartes Paris, France. ${ }^{8}$ Faculté de Médecine Paris Descartes, CHU Cochin Paris France. ${ }^{9}$ IFR 140 Biosit, Plate-forme Amadeus, Université de Rennes1 Rennes France. ${ }^{10}$ UMR CNRS 6290, Institut de Génétique et Développement, CS 34317 Rennes cedex 35043, France.

Received: 11 April 2012 Accepted: 18 June 2012

Published: 9 July 2012

\section{References}

1. Mendelian Inheritance in Man. [http://www.ncbi.nlm.gov/omim]

2. Hoffman EP, Brown RH, Kunkel LM: Dystrophin: the protein product of the Duchenne muscular dystrophy locus. Cell 1987, 51:919-928.

3. Koenig M, Hoffman EP, Bertelson CJ, Monaco AP, Feener C, Kunkel LM: Complete cloning of the Duchenne muscular dystrophy (DMD) cDNA and preliminary genomic organization of the DMD gene in normal and affected individuals. Cell 1987, 50:509-517.

4. Roberts RG, Bobrow M: Dystrophins in vertebrates and invertebrates. Hum Mol Genet 1998, 7:589-595.

5. Segalat L: Dystrophin and functionally related proteins in the nematode Caenorhabditis elegans. Neuromuscul Disord 2002, 12(Suppl 1):S105-S109.

6. Koenig M, Monaco AP, Kunkel LM: The complete sequence of dystrophin predicts a rod-shaped cytoskeletal protein. Cell 1988, 53:219-226.

7. Winder SJ, Gibson TJ, Kendrick-Jones J: Dystrophin and utrophin: the missing links! FeBS lett 1995, 369:27-33.

8. Le Rumeur E, Winder SJ, Hubert JF: Dystrophin: More than just the sum of its parts. Biochim Biophys Acta 2010, 1804:1713-1722

9. Blake DJ, Weir A, Newey SE, Davies KE: Function and genetics of dystrophin and dystrophin-related proteins in muscle. Physiol Rev 2002, 82:291-329.

10. Campbell K, Kahl S: Association of dystrophin and an integral membrane glycoprotein. Nature 1989, 338:259-262

11. Chamberlain JS, Corrado K, Rafael JA, Cox GA, Hausser M, Lumeng C: Interactions between dystrophin and the sarcolemma membrane. Soc Gen Physiol Ser 1997, 52:19-29.

12. Petrof BJ, Shrager JB, Stedmann HH, Kelly AM, Sweeney HL: Dystrophin protects the sarcolemma from stresses developed during muscle contraction. Proc Natl Acad Sci, USA 1993, 90:3710-3714.

13. Deconinck N, Dan B: Pathophysiology of duchenne muscular dystrophy: current hypotheses. Pediatr Neurol 2007, 36:1-7.

14. Batchelor CL, Winder SJ: Sparks, signals and shock absorbers: how dystrophin loss causes muscular dystrophy. Trends Cell Biol 2006, 16:198-205.

15. Desguerre I, Christov C, Mayer M, Zeller R, Becane HM, Bastuji-Garin S, Leturca F, Chiron C, Chelly J, Gherardi RK: Clinical heterogeneity of duchenne muscular dystrophy (DMD): definition of sub-phenotypes and predictive criteria by long-term follow-up. PLOS One 2009, 4:e4347.

16. Koenig M, Beggs A, Moyer M, Scherpf S, Heindrich K, Bettecken T, Meng G, Muller $\mathrm{C}$, Lindlof M, Kaariainen $\mathrm{H}$ : The molecular basis for Duchenne versus Becker muscular dystrophy: correlation of severity with type of deletion. Am J Hum Genet 1989, 45:498-506.

17. Magri F, Govoni A, D'Angelo MG, Del Bo R, Ghezzi S, Sandra G, Turconi AC, Sciacco M, Ciscato P, Bordoni A, et al: Genotype and phenotype characterization in a large dystrophinopathic cohort with extended follow-up. J Neurol 2011, 258:1610-1623.

18. Beggs A, Hoffman E, Snyder J, Arahata K, Specht L, Shapiro F, Angelini C, Sugita $H$, Kunkel L: Exploring the molecular basis for variability among patients with Becker muscular dystrophy: dystrophin gene and protein studies. Am J Hum Genet 1991, 49:54-67.

19. Bushby KM, Gardner-Medwin D, Nicholson LV, Johnson MA, Haggerty ID, Cleghorn NJ, Harris JB, Bhattacharya SS: The clinical, genetic and 
dystrophin characteristics of Becker muscular dystrophy. II. Correlation of phenotype with genetic and protein abnormalities. J Neurol 1993, 240:105-112.

20. Comi GP, Prelle A, Bresolin N, Moggio M, Bardoni A, Gallanti A, Vita G, Toscano A, Ferro MT, Bordoni A, et al: Clinical variability in Becker muscular dystrophy. Genetic, biochemical and immunohistochemical correlates. Brain 1994, 117(Pt 1):1-14.

21. Nigro V, Nigro G, Esposito MG, Comi LI, Molinari AM, Puca GA, Politano L: Novel small mutations along the DMD/BMD gene associated with different phenotypes. Hum Mol Genet 1994, 3:1907-1908.

22. Morandi L, Mora M, Confalonieri V, Barresi R, Di Blasi C, Brugnoni R, Bernasconi P, Mantegazza R, Dworzak F, Antozzi C, et al: Dystrophin characterization in BMD patients: correlation of abnormal protein with clinical phenotype. J Neurol Sci 1995, 132:146-155.

23. Beroud C, Tuffery-Giraud S, Matsuo M, Hamroun D, Humbertclaude V, Monnier N, Moizard MP, Voelckel MA, Calemard LM, Boisseau P, et al: Multiexon skipping leading to an artificial DMD protein lacking amino acids from exons 45 through 55 could rescue up to $63 \%$ of patients with Duchenne muscular dystrophy. Hum Mutat 2007, 28:196-202.

24. Kaspar RW, Allen HD, Ray WC, Alvarez CE, Kissel JT, Pestronk A, Weiss RB, Flanigan KM, Mendell JR, Montanaro F: Analysis of dystrophin deletion mutations predicts age of cardiomyopathy onset in becker muscular dystrophy. Circ Cardiovasc Genet 2009, 2:544-551.

25. Cunniff C, Andrews J, Meaney FJ, Mathews KD, Matthews D, Ciafaloni E, Miller TM, Bodensteiner JB, Miller LA, James KA, et al: Mutation analysis in a population-based cohort of boys with Duchenne or Becker muscular dystrophy. J Child Neurol 2009, 24:425-430.

26. Monaco A, Bertelson C, Liechti-Gallati S, Moser H, Kunkel L: An explanation for the phenotypic differences between patients bearing partial deletions of the DMD locus. Genomics 1988, 2:90-95.

27. Aartsma-Rus A, Van Deutekom JC, Fokkema IF, Van Ommen GJ, Den Dunnen JT: Entries in the Leiden Duchenne muscular dystrophy mutation database: an overview of mutation types and paradoxical cases that confirm the reading-frame rule. Muscle Nerve 2006, 34:135-144.

28. Winnard AV, Klein CJ, Coovert DD, Prior T, Papp A, Snyder P, Bulman DE, Ray PN, McAndrew P, King W, et al: Characterization of translational frame exception patients in Duchenne/Becker muscular dystrophy. Hum Mol Genet 1993, 2:737-744.

29. Hattori N, Kaido M, Nishigaki T, Inui K, Fujimura H, Nishimura T, Naka T, Hazama T: Undetectable dystrophin can still result in a relatively benign phenotype of dystrophinopathy. Neuromuscul Disord 1999, 9:220-226.

30. Tuffery-Giraud S, Saquet C, Thorel D, Disset A, Rivier F, Malcolm S, Claustres M: Mutation spectrum leading to an attenuated phenotype in dystrophinopathies. Eur J Hum Genet 2005, 13:1254-1260.

31. Gualandi F, Neri M, Bovolenta M, Martoni E, Rimessi P, Fini S, Spitali P, Fabris M, Pane M, Angelini C, et al: Transcriptional behavior of DMD gene duplications in DMD/BMD males. Hum Mutat 2009, 30:E310-E319.

32. Anthony K, Cirak S, Torelli S, Tasca G, Feng L, Arechavala-Gomeza V, Armaroli A, Guglieri M, Straathof CS, Verschuuren JJ, et al: Dystrophin quantification and clinical correlations in Becker muscular dystrophy: implications for clinical trials. Brain 2011, 134:3544-3556.

33. van Deutekom JC, Janson AA, Ginjaar IB, Frankhuizen WS, Aartsma-Rus A, Bremmer-Bout M, den Dunnen JT, Koop K, van der Kooi AJ, Goemans NM, et al: Local dystrophin restoration with antisense oligonucleotide PRO051. N Engl J Med 2007, 357:2677-2686.

34. Kinali M, Arechavala-Gomeza V, Feng L, Cirak S, Hunt D, Adkin C, Guglieri M, Ashton E, Abbs S, Nihoyannopoulos $P$, et al: Local restoration of dystrophin expression with the morpholino oligomer AVI-4658 in Duchenne muscular dystrophy: a single-blind, placebo-controlled, doseescalation, proof-of-concept study. Lancet Neurol 2009, 8:918-928.

35. Cirak S, Arechavala-Gomeza V, Guglieri M, Feng L, Torelli S, Anthony K, Abbs S, Garralda ME, Bourke J, Wells DJ, et al: Exon skipping and dystrophin restoration in patients with Duchenne muscular dystrophy after systemic phosphorodiamidate morpholino oligomer treatment: an open-label, phase 2, dose-escalation study. Lancet 2011, 378:595-605.

36. Goemans NM, Tulinius $M$, van den Akker JT, Burm BE, Ekhart PF, Heuvelmans N, Holling T, Janson AA, Platenburg GJ, Sipkens JA, et al: Systemic administration of PRO051 in Duchenne's muscular dystrophy. N Engl J Med 2011, 364:1513-1522.

37. Leiden Muscular Dystrophy pages. [http://www.dmd.nl/nmdb/home.php? select_db=DMD]
38. White SJ, den Dunnen JT: Copy number variation in the genome; the human DMD gene as an example. Cytogenet Genome Res 2006, 115:240-246.

39. UMD-DMD France. [http://www.umd.be/DMD/W_DMD/index.html]

40. Tuffery-Giraud S, Beroud C, Leturcq F, Yaou RB, Hamroun D, Michel-Calemard L, Moizard MP, Bernard R, Cossee M, Boisseau P, et al: Genotype-phenotype analysis in 2,405 patients with a dystrophinopathy using the UMD-DMD database: a model of nationwide knowledgebase. Hum Mutat 2009, 30:934-945.

41. Campbell KP: Three muscular dystrophies: loss of cytoskeleton-extracellular matrix linkage. Cell 1995, 80:675-679.

42. MAMP. [http://www.mamp.info/en/index.html]

43. BioGenouest Platform. [http://www.genouest.org]

44. MyDomains. [http://prosite.expasy.org/mydomains/]

45. Jmol. [http://www.jmol.org]

46. Chelly J, Hamard G, Koulakoff A, Kaplan JC, Kahn A, Berwald-Netter Y: Dystrophin gene transcribed from different promoters in neuronal and glial cells. Nature 1990, 344:64-65.

47. D'Souza VN, Nguyen TM, Morris GE, Karges W, Pillers DA, Ray PN: A novel dystrophin isoform is required for normal retinal electrophysiology. Hum Mol Genet 1995, 4:837-842.

48. Lidov HG, Selig S, Kunkel LM: Dp140: a novel 140 kDa CNS transcript from the dystrophin locus. Hum Mol Genet, 4:329-335.

49. Byers TJ, Lidov HG, Kunkel LM: An alternative dystrophin transcript specific to peripheral nerve. Nat Genet, 4:77-81

50. Hugnot JP, Gilgenkrantz H, Vincent N, Chafey P, Morris GE, Monaco AP, Berwald-Netter Y, Koulakoff A, Kaplan JC, Kahn A, et al: Distal transcript of the dystrophin gene initiated from an alternative first exon and encoding a 75-kDa protein widely distributed in nonmuscle tissues. Proc Natl Acad Sci U S A, 89:7506-7510.

51. Norwood F, Sutherland-Smith A, Keep N, Kendrick-Jones J: The structure of the N-terminal actin-binding domain of human dystrophin and how mutations in this domain may cause Duchenne or Becker muscular dystrophy. Structure 2000, 8:481-491.

52. Huang $X$, Poy F, Zhang R, Joachimiak A, Sudol M, Eck MJ: Structure of a WW domain containing fragment of dystrophin in complex with beta-dystroglycan. Nat Struct Biol 2000, 7:634-638.

53. Legrand B, Giudice E, Nicolas A, Delalande O, LeRumeur E: Computational study of the human dystrophin repeats: interaction properties and molecular dynamics. PLoS One 2011, 6:e23819.

54. Human Genome Variation Society. [http://www.hgvs.org/].

55. Roy A, Kucukural A, Zhang Y: I-TASSER: a unified platform for automated protein structure and function prediction. Nat Protoc 2010, 5:725-738.

56. Zhang Y: I-TASSER server for protein 3D structure prediction. BMC Bioinforma 2008, 9:40.

57. DeLano WL: (Ed): The PyMOL user's manual. San Carlos, CA: DeLano Scientific; 2002.

58. Sippl MJ: Recognition of errors in three-dimensional structures of proteins. Proteins 1993, 17:355-362.

59. Wiederstein M, Sippl MJ: ProSA-web: interactive web service for the recognition of errors in three-dimensional structures of proteins. Nucleic Acids Res 2007, 35:W407-W410.

60. Bowie JU, Luthy R, Eisenberg D: A method to identify protein sequences that fold into a known three-dimensional structure. Science 1991, 253:164-170.

61. Luthy R, Bowie JU, Eisenberg D: Assessment of protein models with three-dimensional profiles. Nature 1992, 356:83-85.

62. Menhart N: Hybrid spectrin type repeats produced by exon-skipping in dystrophin. Biochim Biophys Acta 2006, 1764:993-999.

63. Yokota T, Duddy W, Patridge T: Optimizing exon skipping therapies for DMD. Acta Myologica 2007, 26:179-184.

64. Lupas A: Coiled coils: new structures and new functions. Trends Biochem Sci 1996, 21:375-382

65. Parry DAD, Fraser RDB, John M, Squire JM: Fifty years of coiled-coils and alpha-helical bundles: a close relationship between sequence and structure. J Struct Biol 2008, 163:258-269.

66. Leiden Open Variation Database. [http://www.lovd.nl/2.0/]

67. Fokkema IF, den Dunnen JT, Taschner PE: LOVD: easy creation of a locus-specific sequence variation database using an "LSDB-in-a-box" approach. Hum Mutat 2005, 26:63-68. 
68. UMD. [http://www.umd.be/]

69. Beroud C, Hamroun D, Collod-Beroud G, Boileau C, Soussi T, Claustres M: UMD (Universal Mutation Database): 2005 update. Hum Mutat 2005, 26:184-191.

70. Bushby KM, Thambyayah M, Gardner-Medwin D: Prevalence and incidence of Becker muscular dystrophy. Lancet 1991, 337:1022-1024.

71. Harper SQ, Hauser MA, DelloRusso C, Duan D, Crawford RW, Phelps SF, Harper HA, Robinson AS, Engelhardt JF, Brooks SV, Chamberlain JS: Modular flexibility of dystrophin: implications for gene therapy of Duchenne muscular dystrophy. Nature Med 2002, 8:253-261.

72. Banuelos S, Saraste M, Djinovic Carugo K: Structural comparisons of calponin homology domains: implications for actin binding. Structure 1998, 6(11):1419-1431.

73. Marchler-Bauer A, Anderson JB, Chitsaz F, Derbyshire MK, DeWeese-Scott C, Fong JH, Geer LY, Geer RC, Gonzales NR, Gwadz M, et al: CDD: specific functional annotation with the Conserved Domain Database. Nucleic Acids Res 2009, 37(Database issue):D205-D210.

74. Letunic I, Doerks T, Bork P: SMART 6: recent updates and new developments. Nucleic Acids Res 2009, 37(Database issue):D229-D232

75. Finn RD, Mistry J, Tate J, Coggill P, Heger A, Pollington JE, Gavin OL, Gunasekaran P, Ceric G, Forslund K, et al: The Pfam protein families database. Nucleic Acids Res 2010, 38(Database issue):D211-D222.

76. Koenig M, Kunkel LM: Detailed analysis of the repeat domain of dystrophin reveals four potential hinge segments that may confer flexibility. J Biol Chem 1990, 265(8):4560-4566.

77. Ishikawa-Sakurai M, Yoshida M, Imamura M, Davies KE, Ozawa E: ZZ domain is essentially required for the physiological binding of dystrophin and utrophin to beta-dystroglycan. Hum Mol Genet 2004, 13(7):693-702

78. Hnia K, Zouiten D, Cantel S, Chazalette D, Hugon G, Fehrentz JA, Masmoudi A, Diment A, Bramham J, Mornet D, Winder SJ: ZZ domain of dystrophin and utrophin: topology and mapping of a beta-dystroglycan interaction site. Biochem J 2007, 3(3):667-677. 3.

79. Koenig M, Monaco AP, Kunkel LM: The complete sequence of dystrophin predicts a rod-shaped cytoskeletal protein. Cell 1988, 53(2):219-228.

80. Stone MR, O'Neill A, Catino D, Bloch RJ: Specific interaction of the actinbinding domain of dystrophin with intermediate filaments containing keratin 19. Mol biol cell 2005, 16(9):4280-4293.

81. Legardinier S, Raguenes-Nicol C, Tascon C, Rocher C, Hardy S, Hubert JF, Le Rumeur E: Mapping of the lipid-binding and stability properties of the central rod domain of human dystrophin. J Mol Biol 2009, 389(3):546-558.

82. Yamashita K, Suzuki A, Satoh Y, Ide M, Amano Y, Masuda-Hirata M, Hayashi YK, Hamada K, Ogata K, Ohno S: The 8th and 9th tandem spectrin-like repeats of utrophin cooperatively form a functional unit to interact with polarityregulating kinase PAR-1b. Biochem Biophys Res Commun 2010, 391(1):812-817.

83. Amann KJ, Renley BA, Ervasti JM: A cluster of basic repeats in the dystrophin rod domain binds F-actin through an electrostatic interaction. J Biol Chem 1998, 273(43):28419-28423.

84. Bhosle RC, Michele DE, Campbell KP, Li Z, Robson RM: Interactions of intermediate filament protein synemin with dystrophin and utrophin. Biochem Biophys Res Commun 2006, 346(3):768-777.

85. Lai Y, Thomas GD, Yue Y, Yang HT, Li D, Long C, Judge L, Bostick B, Chamberlain JS, Terjung RL, Duan D: Dystrophins carrying spectrin-like repeats 16 and 17 anchor nNOS to the sarcolemma and enhance exercise performance in a mouse model of muscular dystrophy. J Clin Investig 2009, 119(3):624-635.

86. Rezniczek GA, Konieczny P, Nikolic B, Reipert S, Schneller D, Abrahamsberg C, Davies KE, Winder SJ, Wiche G: Plectin If scaffolding at the sarcolemma of dystrophic (mdx) muscle fibers through multiple interactions with betadystroglycan. J Cell Biol 2007, 176(7):965-977.

87. Newey SE, Benson MA, Ponting CP, Davies KE, Blake DJ: Alternative splicing of dystrobrevin regulates the stoichiometry of syntrophin binding to the dystrophin protein complex. Curr Biol 2000, 10(20):1295-1298.

88. Sadoulet-Puccio HM, Rajala M, Kunkel LM: Dystrobrevin and dystrophin: an interaction through coiled-coil motifs. Proc Natl Acad Sci U S A 1997 94(23):12413-12418.

89. Reynolds JG, McCalmon SA, Donaghey JA, Naya FJ: Deregulated protein kinase A signaling and myospryn expression in muscular dystrophy. $J$ Biol Chem 2008, 283(13):8070-8074.
90. Ayalon G, Davis JQ, Scotland PB, Bennett V: An ankyrin-based mechanism for functional organization of dystrophin and dystroglycan. Cell 2008, 135(7):1189-1200.

91. Flanigan KM, Dunn DM, von Niederhausern A, Soltanzadeh P, Gappmaier E, Howard MT, Sampson JB, Mendell JR, Wall C, King WM, et al: Mutational spectrum of DMD mutations in dystrophinopathy patients: application of modern diagnostic techniques to a large cohort. Hum Mutat 2009, 30(12):1657-1666.

92. Taylor PJ, Maroulis S, Mullan GL, Pedersen RL, Baumli A, Elakis G, Piras S, Walsh C, Prosper-Gutierrez B, De La Puente-Alonso F, et al: Measurement of the clinical utility of a combined mutation detection protocol in carriers of Duchenne and Becker muscular dystrophy. J Med Genet 2007, 44(6):368-372

93. Dent KM, Dunn DM, von Niederhausern AC, Aoyagi AT, Kerr L, Bromberg MB, Hart KJ, Tuohy T, White S, den Dunnen JT, et al: Improved molecular diagnosis of dystrophinopathies in an unselected clinical cohort. Am J Med Genet A 2005, 134(3):295-298.

94. Taylor PJ, Betts GA, Maroulis S, Gilissen C, Pedersen RL, Mowat DR, Johnston HM, Buckley MF: Dystrophin gene mutation location and the risk of cognitive impairment in Duchenne muscular dystrophy. PLoS One 2009, 5(1):8803.

95. Nevo Y, Muntoni F, Sewry C, Legum C, Kutai M, Harel S, Dubowitz V: Large inframe deletions of the rod-shaped domain of the dystrophin gene resulting in severe phenotype. Isr Med Assoc J 2003, 5(2):94-97.

96. Carsana A, Frisso G, Tremolaterra MR, Lanzillo R, Vitale DF, Santoro L, Salvatore F: Analysis of dystrophin gene deletions indicates that the hinge III region of the protein correlates with disease severity. Ann Hum Genet 2005, 69(Pt 3):253-259.

97. Tsukamoto H, Inui K, Fukushima H, Nishigaki T, Taniike M, Tanaka J, Okada S: Molecular study of Duchenne and Becker muscular dystrophies in Japanese. J Inherit Metab Dis 1991, 14(5):819-824.

98. Janssen B, Hartmann C, Scholz V, Jauch A, Zschocke J: MLPA analysis for the detection of deletions, duplications and complex rearrangements in the dystrophin gene: potential and pitfalls. Neurogenetics 2005, 6(1):29-35.

99. Buzin $\mathrm{CH}$, Feng J, Yan J, Scaringe W, Liu Q, den Dunnen J, Mendell JR, Sommer SS: Mutation rates in the dystrophin gene: a hotspot of mutation at a CpG dinucleotide. Hum Mutat 2005, 25(2):177-188

100. Ramelli GP, Joncourt F, Luetschg J, Weis J, Tolnay M, Burgunder JM: Becker muscular dystrophy with marked divergence between clinical and molecular genetic findings: case series. Swiss Med Wkly 2006, 136(11-12):189-193.

101. Fajkusova L, Lukas Z, Tvrdikova M, Kuhrova V, Hajek J, Fajkus J: Novel dystrophin mutations revealed by analysis of dystrophin mRNA: alternative splicing suppresses the phenotypic effect of a nonsense mutation. Neuromuscul Disord 2001, 11(2):133-138.

102. Prior TW, Bridgeman SJ: Experience and strategy for the molecular testing of Duchenne muscular dystrophy. J Mol Diagn 2005, 7(3):317-326.

doi:10.1186/1750-1172-7-45

Cite this article as: Nicolas et al: Assessment of the structural and functional impact of in-frame mutations of the $D M D$ gene, using the tools included in the eDystrophin online database. Orphanet Journal of Rare Diseases 2012 7:45.

\section{Submit your next manuscript to BioMed Central and take full advantage of:}

- Convenient online submission

- Thorough peer review

- No space constraints or color figure charges

- Immediate publication on acceptance

- Inclusion in PubMed, CAS, Scopus and Google Scholar

- Research which is freely available for redistribution 